\title{
Article \\ A Comparative Performance Evaluation of Routing Protocols for Flying Ad-Hoc Networks in Real Conditions
}

\author{
Antonio Guillen-Perez *D, Ana-Maria Montoya, Juan-Carlos Sanchez-Aarnoutse and Maria-Dolores Cano * $\mathbb{D}$ \\ Department of Information Technologies and Communications, Universidad Politécnica de Cartagena, \\ 30203 Murcia, Spain; anamaria.montoya.osete@gmail.com (A.-M.M.); juanc.sanchez@upct.es (J.-C.S.-A.) \\ * Correspondence: antonio.guillen@edu.upct.es (A.G.-P.); mdolores.cano@upct.es (M.-D.C.)
}

Citation: Guillen-Perez, A.;

Montoya, A.-M.; Sanchez-Aarnoutse,

J.-C.; Cano, M.-D. A Comparative

Performance Evaluation of Routing

Protocols for Flying Ad-Hoc

Networks in Real Conditions.

Appl. Sci. 2021, 11, 4363. https://

doi.org/10.3390/app11104363

Academic Editor: Sylvain Bertrand

Received: 30 March 2021

Accepted: 10 May 2021

Published: 11 May 2021

Publisher's Note: MDPI stays neutral with regard to jurisdictional claims in published maps and institutional affiliations.

Copyright: (c) 2021 by the authors. Licensee MDPI, Basel, Switzerland. This article is an open access article distributed under the terms and conditions of the Creative Commons Attribution (CC BY) license (https:/ / creativecommons.org/licenses/by/ $4.0 /)$.

\begin{abstract}
Unmanned aerial vehicles (UAVs) are widely used in our modern society and their development is rapidly accelerating. Flying Ad Hoc Networks (FANETs) have opened a new window of opportunity to create new value-added services. However, the characteristics that make FANETs unique, such as node mobility, node distance, energy constraints, etc., imply that several guidelines need to be considered for their successful deployment. Although numerous routing protocols have been proposed for FANETs, due to the wide range of applications in which FANETs can be applied, not all routing protocols can be used. Due to this challenge, after breaking down and classifying the different types of existing routing protocols for FANET, this paper analyzes and compares the performance of several routing protocols (Babel, BATMAN-ADV, and OLSR) in terms of throughput and packet loss in a real deployment composed of several UAV nodes using 2.4 and $5 \mathrm{GHz}$ WiFi networks. The results show that Babel achieves better performance in the studied metrics than OLSR and BATMAN-ADV, while BATMAN-ADV delivers significantly lower performance. This experimental study confirms the importance of choosing the proper routing protocol for FANETs and their performance evaluation, something that will be extremely important in a few years when this type of network will be common in our day-to-day life.
\end{abstract}

Keywords: ad hoc networks; experimental study; Flying Ad Hoc Networks; FANET; practical case; routing protocols; testbed; unmanned aerial vehicles; UAV; WiFi

\section{Introduction}

Ad hoc networks are becoming an essential part of our modern technological infrastructure, expanding the range of available applications and their characteristics. On the other hand, thanks to technological advances, unmanned aerial vehicles (UAVs) offer a wide range of possibilities (extending wireless coverage, use in agriculture, search and rescue, fire surveillance, etc.). The creation of an ad hoc network with UAVs also offers a significant advantage over other networks due to the high mobility of its nodes and their great versatility. This type of network is known as a Flying Ad Hoc Network (FANET) and is considered a subtype of Mobile Ad Hoc Networks (MANETs) or Vehicular Ad Hoc Networks (VANET). Due to the particular characteristics of UAVs, they bring new challenges for obtaining node mobility models, routing protocols, energy management, etc. Indeed, FANETs present high mobility of their nodes, both in speed and 3D mobility, frequent changes of network topology, or intense energy and weight restrictions. Consequently, it is essential to carry out a study of the different protocols for FANETs to identify the best ones to minimize the impact of the UAVs' characteristics and create a dynamic, agile, and efficient FANET network. A survey of mobility models, positioning algorithms, and propagation models can be found in [1-3].

In this work, after analyzing the types of routing protocols designed for FANETs, we focus on comparing, through a real deployment of a FANET using the IEEE 802.11 (WiFi) standard in the $2.4 \mathrm{GHz}$ and $5 \mathrm{GHz}$ bands, the performance offered by several routing 
protocols. We believe that a real deployment can provide much more reliable results than those obtained by simulators. Therefore, we consider that the highlight of this article is the actual deployment of the FANET, something that, as we will see, very few articles do, which limits their investigation to simulated experiments. The chosen protocols are Optimized Link-State Routing (OLSR), Better Approach to Mobile Ad Hoc Networking Advanced (BATMAN-ADV), and Babel. They are compared in terms of throughput and packet losses in a network composed of several UAVs and an intermediate relay node. We chose these proactive routing protocols because of their high mobility range, low latency, widespread use in ad hoc networks, and good power consumption; similarly, they have relatively low complexity and computational demands, allowing us to simplify and automate some of the challenges mentioned in [1-3]. The results highlight the importance of the correct choice of routing protocol for FANETs, showing that Babel achieves higher performance in the studied metrics whereas BATMAN-ADV and OLSR show lower performance.

The rest of the article is organized as follows: in Section 2, we include a review of state-of-the-art case studies with FANETs, and we break down the different types of routing protocols proposed for ad hoc networks and FANETs. The FANET deployed for this study and the tools used are detailed in Section 3. The results are discussed in Section 4. Finally, conclusions and future works are presented in Section 5.

\section{State of the Art}

In this section, we will look at proposed works for FANETs. First, we will look at the proposed studies that perform a real FANET deployment, and then we will see the different routing protocols proposed for ad hoc networks and FANETs.

\subsection{Real Experimental Studies}

In this subsection, we will see a compilation of papers that analyze, by means of real experimental studies, the performance of FANETs deployed by UAVs. Due to the high cost and complexity of building large-scale networks with variable topologies, and the difficulties related to the repetition of scenarios, it is challenging to find works that include real deployments of FANETs. The vast majority of the work completed expects the simulators used to be capable of simulating real conditions to ensure that the results they obtain or the algorithms they propose can resemble what could be obtained. However, we believe that a real deployment, controlling as many variables as possible and repeating the experiments several times, can provide greater assurance. The results obtained are, by comparison, more trustworthy. That is why we consider this work very interesting, helping the reader to understand the impact of choosing a routing protocol on the FANET performance.

Analyzing works that focus on real FANET deployments, Rosati et al. [4] studied the performance offered by Predictive-OLSR (P-OLSR) and OLSR in a FANET composed of two small fixed-wing UAVs (called "eBee"). Their results showed that, because P-OLSR uses GPS information, the performance obtained both in simulation and in experimental tests improves that obtained with OLSR, reducing the number of communication interruptions.

Furthermore, the P-OLSR performance was compared against OLSR and Babel in [5]. The results showed that P-OLSR, for the scenario they proposed (up to three UAVs with a highly dynamic ad hoc network), could provide more reliable multi-hop communication than Babel and OLSR.

In [6], the authors compared two modes of operation of the $802.11 \mathrm{WiFi}$ standard (access point and ad hoc using BATMAN-ADV) in a real experimental scenario in terms of coverage, throughput, and energy efficiency with up to two quadcopter UAVs. The results revealed a better performance of the access point mode in terms of received signal strength and throughput but worse performance in terms of power consumption than the ad hoc mode.

The work presented by Lee et al. [7] proposed an approach similar to P-OLSR, in which the UAV nodes employed GPS information to improve the routing protocol, called Ground Control System-Routing (GCS-R). A real experiment was conducted with up to six 
UAVs in a network-coverage application scenario. The results showed that their proposed routing algorithm outperformed OLSR and DSDV in terms of throughput, stability, and network outage time. However, given that it suggests a centralized algorithm, it has a single point of failure that could be critical because of the instability of the UAV nodes and presents serious scalability problems.

On the other hand, in [8], the authors showed the deployment of a FANET using BATMAN as the routing protocol, showing the capabilities that this type of network can offer in terms of coverage and throughput. They used a UAV in three different scenarios, and the results showed that the maximum distance they could transmit without packet loss was $117 \mathrm{~m}$.

Finally, the authors of [9] proposed a security protocol for FANETs called SUAP, which incorporates geographical leashes, hash chains, and public-key cryptography into the AODV routing protocol. Although SUAP proved to be effective in encrypting messages exchanged between nodes against various attacks, it did not provide a robust mechanism to recover from disconnections between nodes. According to the experimental result performed with three nodes, the delay to re-establish a new route when a node failure occurred was considerable, especially for real-time applications such as video capture, monitoring, and aerial photography. Moreover, its performance should be evaluated in a network with a high density of nodes. A summary of the reviewed papers can be seen in Table 1.

Table 1. Related works that included a real FANET deployment. Also detailed are the routing protocols employed and the number of UAVs.

\begin{tabular}{ccc}
\hline Work & Routing Protocols & Number of UAVs \\
\hline Rosati et al. [4] & OLSR, P-OLSR & 2 \\
Rosati et al. [5] & Babel, OLSR, P-OLSR & 3 \\
Guillen et al. [6] & BATMAN-ADV & 2 \\
Lee et al. [7] & GCS-R, DSDV, OLSR & 6 \\
Kaysina et al. [8] & BATMAN & 1 \\
Maxa et al. [9] & SUAP & 2 \\
\hline
\end{tabular}

\subsection{Routing Protocols}

Routing protocols are responsible for guaranteeing the delivery of a message from a source node to a destination node. Routing protocols must adapt to the essential characteristics of FANETs: high mobility, energy efficiency, constant changes in the topology, etc. In addition, due to the wide variety of application fields, the requirements of routing protocols in FANETs can be very diverse. For example, a constant jitter would be necessary for real-time video applications, whereas a high level of reliability would be necessary in applications that extend telecommunication coverage in case of disasters (regardless of delay and jitter). Most FANETs' routing protocols are extensions of well-known MANET protocols, such as AODV, OLSR, or DSR [10]. However, there is still a lack of routing protocols that fit all FANETs' needs.

In this subsection, we will examine the different routing protocols proposed for FANETs and group them into five main categories: (i) topology-based, (ii) position-based, (iii) clustering/hierarchical, (iv) swarm-based, and (v) delay-tolerant network (DTN).

\subsubsection{Topology-Based Routing Protocols}

Topology-based routing protocols base their operation on using the links information for data forwarding. Within this category, four types of protocols can be distinguished: (i) static, (ii) proactive, (iii) reactive, and (iv) hybrid.

\section{Static Routing Protocols}

The nodes in this network have static routing tables which are configured at the beginning of a task and do not change. Networks that implement these protocols must 
have a constant topology, and therefore, being unable to adapt dynamically to changes, are susceptible to failures. The static routing protocols include Load Carry and Deliver Routing (LCAD) [11], Multi-Level Hierarchical Routing (MLHR) [12], and Data-Centric Routing (DCR) [13]. LCAD is based on the Store-Carry-Forward (SCF) paradigm [14]. The nodes capture the data and transport it, physically moving the message to a relay or destination node. It is usually used in DTN networks. MLHR solves the problem of scalability by clustering the nodes of the network and allowing a head node to communicate with the other head nodes of other clusters. Thus, the size and area of operation increase, but this head node can be a bottleneck and is a single point of failure [15]. DCR bases the routing on the information contained in the message. Thus, this protocol sends the information to several nodes that want specific data.

\section{Proactive Routing Protocols}

Each node has its routing table which is periodically updated and shared with the other nodes. The routing tables contain the routes to send a message from a source node to any destination node in the network. The main advantage of these types of protocols is their low delay in sending messages because the path is known beforehand. However, if there are many nodes in the network, the periodic updating of the routing tables severely consumes bandwidth and energy. In addition, proactive protocols react slowly to changes in topology, having to update the routing tables of all nodes in the network. Due to these disadvantages, these protocols are not usually used in applications with FANETs with a large number of UAVs with high mobility or when energy consumption must be low. The most important protocols proposed or adapted for FANETs are Optimized Link-State Routing (OLSR) [16], Destination Sequence Distance Vector (DSDV) [17], Better Approach to Mobile Ad Hoc Network (BATMAN) [18], and Directional OLSR (DOLSR) [19]. The OLSR protocol is currently the most widely used routing protocol in ad hoc networks. The approach of this protocol is to put a cost to each link (link-state) in the network. Each node evaluates the cost of sending a message through a link that is directly connected and shares it with its neighboring nodes using a flooding strategy. This cost can be the distance, delay, losses, bandwidth, etc. Once the view of the network has been updated, the route is searched applying the shortest path algorithm (Dijkstra). DSDV is a protocol based on the Bellman-Ford algorithm. It adds two parameters to vector-distance routing, which are a sequence number, to avoid loops and determine the freshness of the routes and the Dampling parameter. In addition, it uses two types of packages for route updates: full-dump and incremental. The full-dump packages contain all the information in the routing table, and due to its size, it is not usually transmitted. The incremental packet is used to update the routes in the last full-dump packet. DSDV has been used extensively in the field of FANETs, as can be seen in [20-22]. The BATMAN routing protocol is a relatively new proactive protocol that is used in MANETs. The BATMAN protocol does not discover the entire network; the protocol only learns from the nodes directly connected to them. In addition, BATMAN-Advanced (BATMAN-ADV) [23] is an improvement of the original BATMAN protocol in terms of performance due to its integration in the protocol stack. Numerous comparative studies of BATMAN-ADV performance in ad hoc networks and FANETs have been carried out $[23,24]$. DOLSR was specifically designed for FANETs and is a variant of OLSR. One of the most important performance factors in OLSR is the selection of multipoint relay (MPR) nodes. Thus, in DOLSR the number of MPRs is reduced to decrease the overhead. Each node selects a set of MPRs so that it can cover two-hop neighbors. DOLSR has the advantage of minimizing end-to-end delay, which is crucial for real-time applications and offers security improvements as it is resistant to jamming. In addition to the protocols explained, there are a variety of protocols with variants that are used in FANETs, such as Predictive-OLSR (P-OLSR) [5], Mobility and Load-Aware OLSR (ML-OLSR) [25], Contention-Based OLSR (COLSR) [26], Modified-OLSR (M-OLSR) [27], Cartography-Enhanced OLSR (CE-OLSR) [28], Topology Broadcast Based on Reverse-Path Forwarding (TBRPF) [29], Fisheye State Routing (FSR) [30], and Babel [31]. Babel builds on 
the ideas of DSDV, AODV, and other routing protocols to derive a loop-avoiding distance vector routing protocol that is designed to be robust and efficient in both relatively stable and highly dynamic networks.

\section{Reactive Routing Protocols}

Due to the large bandwidth consumption that periodically occurs in the network discovery process of proactive protocols, reactive protocols use on-demand network discovery processes, which makes reactive protocols bandwidth-efficient. These protocols have a great advantage over proactive protocols as it gives them a great dynamism, something necessary in FANETs, but it has a great disadvantage in the latency produced by the route-search process. The most important reactive routing protocols are Dynamic Source Routing (DSR) [32], Ad Hoc On-Demand Distance Vector (AODV) [33], and Time-Slotted AODV (TS-AODV) [34]. DSR is a source-routing protocol. The complete route that a packet must follow is indicated in the header and only the source node can indicate the route. AODV is the most popular reactive routing protocol and is typically used in MANETs, VANETs, and FANETs. During the route lookup process, the source node searches its routing table to see if a route to the destination node has been established in the past. If no route exists, a route request process is initiated. TS-AODV is a time slot routing protocol centered on FANETs and based on the AODV protocol. Due to the large number of UAVs that may exist in FANETs, TS-AODV uses the time-division mechanism to avoid collisions in the transmission of information, significantly reducing packet losses and increasing the available bandwidth. In addition to the reactive protocols explained above, there are other routing protocols used in the literature on ad hoc networks and FANETs, such as Multicast AODV (MAODV) [35] and AODV Security (AODVSEC) [36].

\section{Hybrid Routing Protocols}

To solve the problems of bandwidth consumption of control messages and the low dynamism of proactive protocols, as well as the long delay in the route search of reactive protocols, hybrid routing protocols were introduced. These hybrid protocols are particularly suitable for large networks since they base their operation on the division of the network into sub-networks or zones. Thus, a proactive routing protocol operates within each zone and a reactive routing protocol is used for communication between zones. For hybrid solutions, the Zone Routing Protocol (ZRP) [37] is the most popular. ZRP divides the network into clusters of nodes in which their maximum separation distance is predefined. Within the clusters, a proactive routing protocol is applied, and nodes in different zones are routed to a subset that is common to both zones. There are other hybrid protocols designed or modified for FANETs, such as the Temporarily Ordered Routing Algorithm (TORA) [38], Rapid-reestablish TORA (RTORA) [39], Hybrid Wireless Mesh Protocol (HWMP) [40], Sharp Hybrid Adaptive Routing Protocol (SHARP) [41], and Hybrid Routing Protocol (HRP) [42].

\subsubsection{Position-Based Routing Protocols}

These routing protocols base their operation on the knowledge of the geographical position of the nodes. Therefore, they are the most suitable routing protocols for FANETs with high mobility. Protocols in this category can be divided into (i) reactive-based, (ii) greedybased, and (iii) heterogeneous.

\section{Reactive-Based Routing Protocols}

These types of protocols are based on a reactive technique and use the position of the nodes to obtain higher performance. In this category, we highlight the Reactive-GreedyReactive (RGR) algorithm [43]. RGR is based on the reactive routing protocol AODV [33] for the on-demand route lookup process, and for message delivery, it is based on the Greedy Geographic Forwarding (GGF) protocol [44]. Other reactive-based protocols are 
Ad Hoc Routing Protocol for Aeronautical Mobile Ad Hoc Networks (ARPAM) [45] and Multipath Doppler Routing (MUDOR) [46].

Greedy-Based Routing Protocols

This set of protocols searches the path with the least number of hops between nodes through the Greedy Forwarding approach [47], minimizing message delay. One of the most prominent protocols of this category is Geographic Position Mobility-Oriented Routing (GPMOR) [48]. GPMOR was designed considering some characteristics of FANETs and bases its operation on the predictive approach. Based on the Gauss-Markov mobility model [1] and the geographical positions of the nodes, GPMOR predicts the node positions and selects the next closest forwarding node to the receiver optimally, following the Greedy approach. Other greedy-based routing protocols are Mobility Prediction-Based Geographic Routing (MPGR) [49], Geographic Load Share Routing (GLSR) [50], Geographic Greedy Perimeter Stateless Routing (GPSR) [51], Greedy-Hull-Greedy (GHG) [52], Greedy-RandomGreedy (GRG) [53], Greedy Distributed Spanning Tree Routing 3D (GDSTR-3D) [54], and UAV Search Mission Protocol (USMP) [51].

\section{Heterogeneous Routing Protocols}

This set of protocols is applied to networks where the nodes that form them are of different natures, i.e., the network can be formed by fixed or mobile nodes on the ground and the aerial nodes of a FANET. This architecture has several advantages including increased coverage and performance. Within this set of protocols, Connectivity-Based Traffic Density Aware Routing Using UAVs for VANETs (CRUV) [55] stands out. CRUV relies on the existence of a DTN VANET supported by a FANET, which allows the interconnection of the DTN. In addition, there are also the following: UAV-Assisted VANET Routing Protocol (UVAR) [56], Position-Aware Secure and Efficient Routing (PASER) [57], Cross-Layer Link Quality and Geographical-Aware Beaconless (XLinGo) [58], and Secure UAV Ad Hoc Routing Protocol (SUAP) [9].

\subsubsection{Clustering/Hierarchical Routing Protocols}

In this category, UAV nodes are grouped into clusters, in a hierarchical fashion, and within each cluster, there is a node (cluster head) that enables inter-cluster communication via other cluster heads. In these routing protocols, the selection of the node acting as cluster-head is a critical task since the overall performance of the network will depend in part on this node. Within this category of protocols, the Clustering Algorithm of UAV Networking (CAUN) [59], and Mobility Prediction Clustering Algorithm for UAV Networking (MPCA) [60] may be mentioned. The operation of CAUN is quite simple: the initial cluster is built on the ground depending on the mission application, and once the network is deployed, the cluster adapts according to real-time conditions. On the other hand, MPCA predicts network topology updates, and, in turn, determines cluster formation based on UAV mobility, allowing for more stable clusters. In addition to the protocols described above, there are other protocols belonging to the category of clustering/hierarchical routing protocols, such as Landmark Ad Hoc Routing (LANMAR) [61], Multi-Meshed Tree Protocol (MMT) [62], Cluster-Based, Location-Aided DSR (CBLADSR) [63], and Disruption Tolerant Mechanism (DTM) [64].

\subsubsection{Swarm-Based Routing Protocols}

Swarm-based routing protocols are inspired by the behavior of animals and nature. Thus, for example, as swarm-based routing protocols that are created for FANETs, we highlight the BeeAdHoc [65] algorithm that bases its operation on the behavior of bees, as well as AntHocNet [66], and APAR [67] algorithms, both inspired by the behavior of ants. 


\subsubsection{Delay-Tolerant Network (DTN) Routing Protocols}

Delay-tolerant routing protocols are proposed for networks with constant outages, partitions, and topology changes, such as FANETs. Thus, these protocols make use of the Store-Carry-and-Forward (SCF) technique when nodes lose connectivity. This technique eliminates the overhead since no control messages are transmitted but greatly increases the communication delay. The most widespread protocol of this group is Location-Aware Routing for Opportunistic Delay Tolerant (LAROD) [68]. LAROD is based on the combination of two approaches: SCF and Greedy Forwarding techniques, depending on the situation, and uses the beaconless strategy to reduce the overload of the network. In addition, within this category, it is worth highlighting the following algorithms: AeroRP [69], Geographic Routing Protocol for Aircraft Ad Hoc Network (GRAA) [70], Epidemic [71], Maxprop [72], Spray and Wait [73], and Prophet [74].

Table 2 shows a summary of the different classes of routing algorithms, their subclasses in this section, and their algorithms.

Table 2. A summary of routing algorithms and their classes and subclasses.

\begin{tabular}{|c|c|c|}
\hline Type & Subtype & Routing Algorithm \\
\hline \multirow{9}{*}{ Topology-Based } & Static & LCAD [11], MLHR [12], DCR [13] \\
\hline & & OLSR [16], DSDV [17], BATMAN [18], \\
\hline & Propetive & BATMAN-ADV [23], DOLSR [19], P-OLSR [5], \\
\hline & Proactive & ML-OLSR [25], COLSR [26], M-OLSR [27], \\
\hline & & CE-OLSR [28], TBRPF [29], FSR [30], Babel [31] \\
\hline & Renctive & DSR [32], AODV [33], TS-AODV [34], \\
\hline & Reactive & MAODV [35], AODVSEC [36] \\
\hline & & ZRP [37], TORA [38], RTORA [39], \\
\hline & Hybrid & HWMP [40], SHARP [41], HRP [42] \\
\hline \multirow{4}{*}{ Position-Based } & Reactive-Based & RGR [43], GGF [44], ARPAM [45], MUDOR [46] \\
\hline & Croodurased & GPMOR [48], MPGR [49], GLSR [50], GPSR [51], \\
\hline & Greedy-bas & GHG [52], GRG [53], GDSTR-3D [54], USMP [51] \\
\hline & Heterogeneous & $\begin{array}{l}\text { CRUV [55], UVAR [56], PASER [57], } \\
\text { XLinGo [58], SUAP [9] }\end{array}$ \\
\hline Clustering/Hierarchical & & $\begin{array}{l}\text { CAUN [59], MPCA [60], LANMAR [61], } \\
\text { MMT [62], CBLADSR [63], DTM [64] }\end{array}$ \\
\hline Swarm-Based & & BeeAdHoc [65], AntHocNet [66], APAR [67] \\
\hline Delay-Tolerant & & LAROD [68], AeroRP [69], GRAA [70], Epidemic \\
\hline Network & & [71], Maxprop [72], Spray and Wait [73], Prophet [74] \\
\hline
\end{tabular}

\section{Materials, Methods, and Scenario}

In this section, we will explain the testbed and tools employed in this study. By using this deployment, we demonstrate the communication capabilities that FANETs can offer, comparing the performance achieved with various proactive routing protocols, specifically OLSR, BATMAN-ADV, and Babel. The 3 protocols were selected based on the criteria of "state of the art" technology, experience working with them, suitability for the proposed scenario, and compatibility with the communications module.

For this purpose, a WiFi network composed of several UAVs was deployed. Each UAV had a specific communication module (WiTi [75]); see Figure 1a. These communication modules had a dual $2.4 / 5 \mathrm{GHz}$ communication band, using the IEEE $802.11 \mathrm{~g}$ standard for the $2.4 \mathrm{GHz}$ band and the IEEE 802.11a standard for the $5 \mathrm{GHz}$ band, and 2 antennas for each frequency band. The tool iperf3 [76] was employed to evaluate the performance of the different routing algorithms, analyzing throughput and packet losses. To analyze packet losses in an efficient way, the UDP communication protocol was used. In the deployed scenario (see Figure 1b), 5 communication nodes were placed: specifically, 2 UAVs (quadcopters), 2 PCs, and 1 ground node. The 2 PCs were located under the UAVs to simulate devices in a coverage extension scenario. They also allowed monitoring of the network status. On the other hand, the ground node operated as a relay base station, acting as an intermediate node between the drones when the distance between the nodes 
required its use. The relay node was located at $35 \mathrm{~m}$ from PC1 (UAV1). Whereas UAV1 was kept at a fixed location, UAV2 flew horizontally, stopping every $10 \mathrm{~m}$ to take performance measurements. Each measurement had a duration of $60 \mathrm{~s}$ and consisted of sending data between the 2 PCs through the UAVs. Both UAVs flew at an altitude of $10 \mathrm{~m}$, calibrating all distances, positions, and heights with the UAVs' GPS modules. A representation of the deployed scenario can be seen in Figure 2a,b. For instance, this scenario could simulate a situation where a coverage extension is required due to an emergency, to solve a specific moment of overload of the communications network, or for remote surveillance.

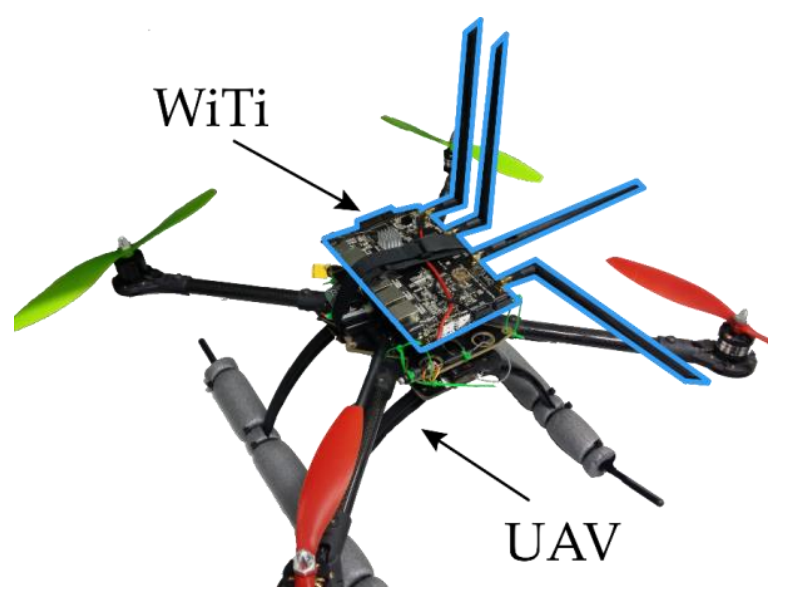

(a)

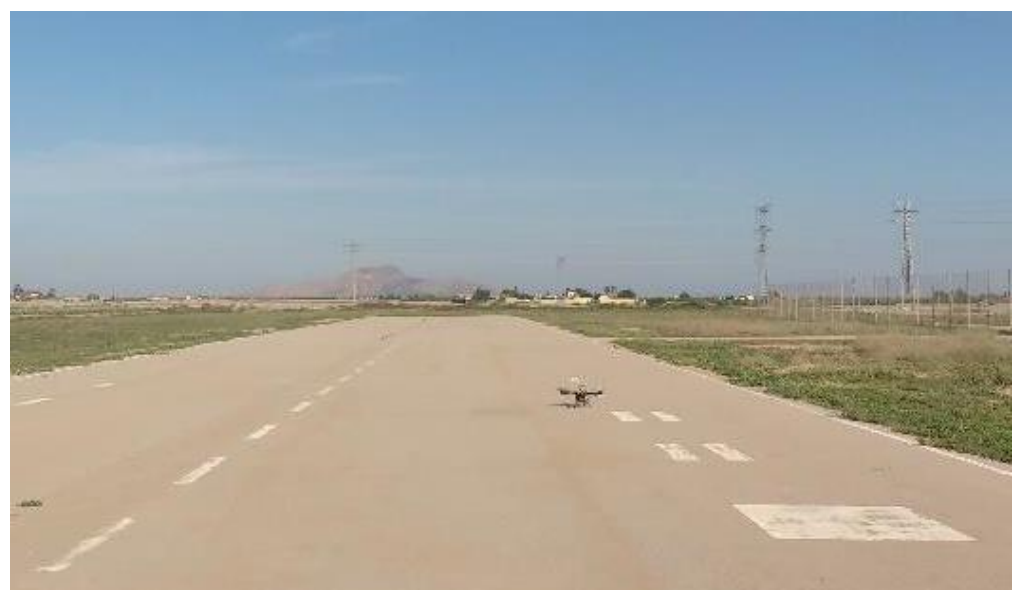

(b)

Figure 1. (a) UAV with WiFi communication module (WiTi). (b) Flying field, "Los Halcones de la Rambla", Murcia, Spain. 


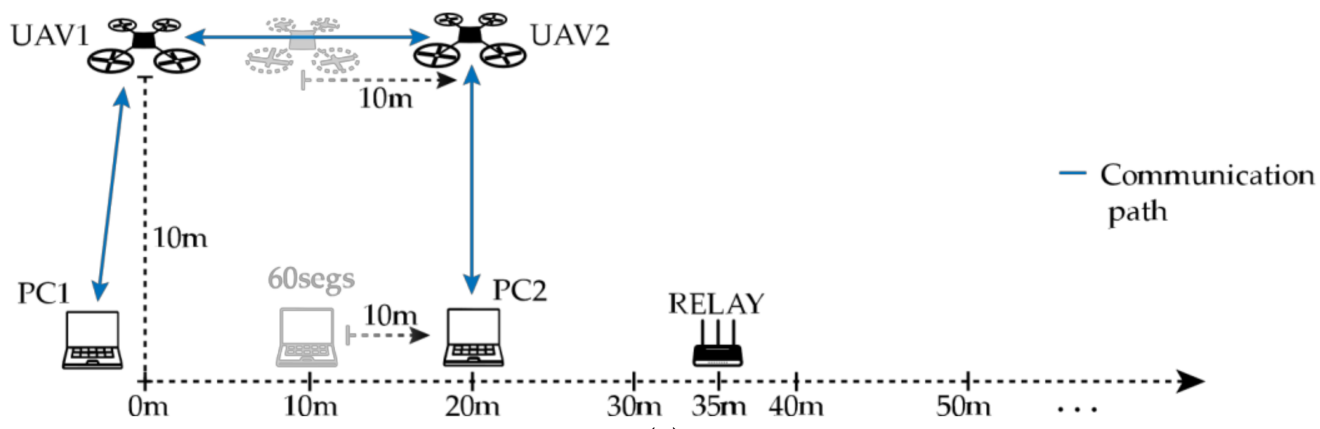

(a)

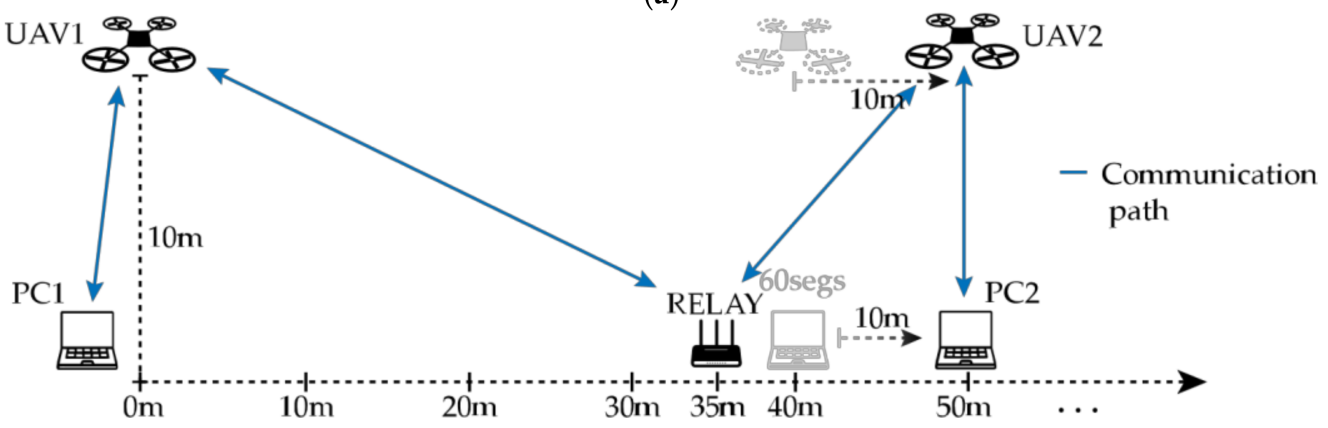

(b)

Figure 2. Real testbed FANET with relay node. (a) Communication before 35-m mark. (b) Communication after 35-m mark. Note that after the 35-m mark, communication between the 2 UAVs (UAV1 and UAV2) was performed through the relay node. Before this mark, the communication was completed through a direct path. Performance measurements were taken between the 2 UAVs every $10 \mathrm{~m}$ step and each measurement had a duration of $60 \mathrm{~s}$. The PCs were used to monitor the network and followed their UAV. The height of the UAVs was $10 \mathrm{~m}$. The first UAV (UAV1) was located at the 0 -meter mark. The relay node was located at the 35-m mark. The second UAV (UAV2) was positioned for $60 \mathrm{~s}$ at the measurement points located $10 \mathrm{~m}$ from the 0 -meter mark. That is, the first measuring point was located at $10 \mathrm{~m}$, the second at $20 \mathrm{~m}$, and so on.

\section{Results}

This section will analyze the results obtained in the tests detailed in the previous section, comparing in terms of throughput and packet losses the different routing algorithms presented.

The results showed that the Babel and OLSR protocols obtained higher throughput in both the $2.4 \mathrm{GHz}$ and $5 \mathrm{GHz}$ bands. Besides, the expected inverse relationship between packet losses and throughput was demonstrated since one increases while the other decreases. It was also observed that the $5 \mathrm{GHz}$ band presented a faster throughput decay. Because the received power is inversely proportional to frequency and distance, the $2.4 \mathrm{GHz}$ band will present a higher received power at equal transmitted power and communication distance, which will allow the maintenance of a more stable and robust communication. Only at $10 \mathrm{~m}, 40 \mathrm{~m}$, and $50 \mathrm{~m}$, the performance of both bands is comparable. For the $10 \mathrm{~m}$ point, the communication between the UAVs was direct on both bands, so propagation losses were low and communication was very stable. For the $40 \mathrm{~m}$ and $50 \mathrm{~m}$ points, the communication for the $2.4 \mathrm{GHz}$ band was still direct. However, for the $5 \mathrm{GHz}$ band, the communication made an intermediate hop through the relay node, decreasing the distance between the communication nodes. Throughput results can be seen in Table 3 and Figure 3 . Likewise, packet loss results are shown in Table 4 and Figure 4. 
Table 3. Average throughput (Mbps) obtained between PCs-UAVs at different gap distances for OLSR, BATMAN-ADV, and Babel, for 2 frequency bands: 2.4 and $5 \mathrm{GHz}$. Each measurement had a duration of $60 \mathrm{~s}$.

\begin{tabular}{|c|c|c|c|c|c|c|c|c|}
\hline \multirow{2}{*}{$\begin{array}{l}\text { Routing } \\
\text { Protocol }\end{array}$} & \multirow{2}{*}{$\begin{array}{c}\text { Frequency } \\
\text { Band }\end{array}$} & \multicolumn{7}{|c|}{ Distance } \\
\hline & & $10 \mathrm{~m}$ & $20 \mathrm{~m}$ & $30 \mathrm{~m}$ & $40 \mathrm{~m}$ & $50 \mathrm{~m}$ & $60 \mathrm{~m}$ & $70 \mathrm{~m}$ \\
\hline \multirow{2}{*}{ OLSR } & $2.4 \mathrm{GHz}$ & 1.02 & 1.05 & 1.05 & 0.75 & 0.91 & 0.84 & 0.00 \\
\hline & $5 \mathrm{GHz}$ & 0.98 & 0.73 & 0.51 & 0.99 & 0.82 & 0.00 & 0.00 \\
\hline \multirow{2}{*}{$\begin{array}{l}\text { BATMAN- } \\
\text { ADV }\end{array}$} & $2.4 \mathrm{GHz}$ & 1.05 & 1.05 & 0.90 & 0.82 & 0.51 & 0.27 & 0.75 \\
\hline & $5 \mathrm{GHz}$ & 0.89 & 0.16 & 0.03 & 0.82 & 0.58 & 0.00 & 0.00 \\
\hline \multirow{2}{*}{ Babel } & $2.4 \mathrm{GHz}$ & 1.05 & 1.05 & 1.05 & 1.05 & 0.93 & 0.67 & 0.86 \\
\hline & $5 \mathrm{GHz}$ & 0.96 & 0.66 & 0.49 & 0.88 & 0.71 & 0.00 & 0.00 \\
\hline
\end{tabular}

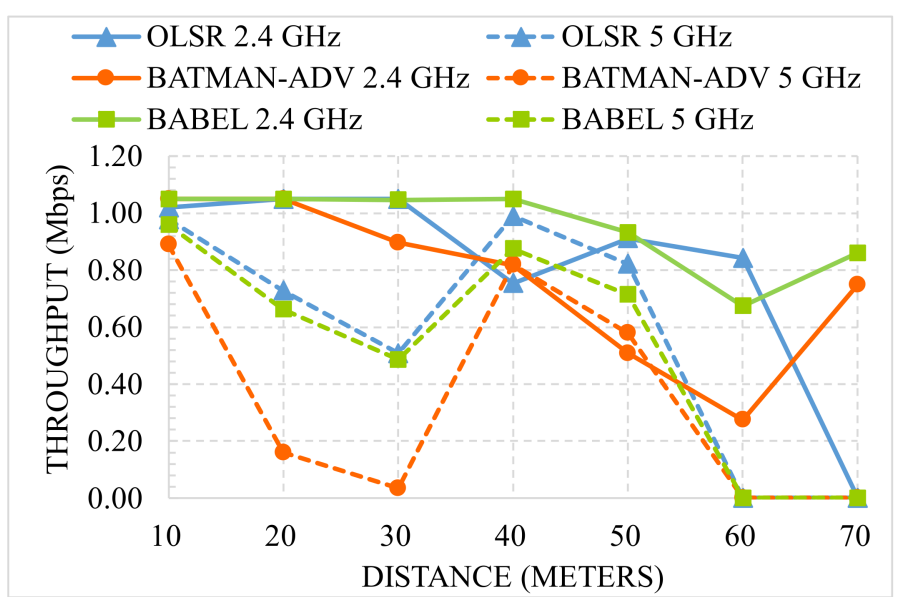

Figure 3. Average throughput (Mbps) vs. distance (meters) for each protocol and frequency band.

Table 4. Average packet loss (\%) obtained between PCs-UAVs at different gap distances for OLSR, BATMAN-ADV, and Babel, for 2 frequency bands: 2.4 and $5 \mathrm{GHz}$. Each measurement had a duration of $60 \mathrm{~s}$.

\begin{tabular}{ccccccccc}
\hline \multirow{2}{*}{ Routing Protocol } & Frequency & \multicolumn{7}{c}{ Distance } \\
\cline { 3 - 8 } & Band & $\mathbf{1 0} \mathbf{~ m}$ & $\mathbf{2 0} \mathbf{~ m}$ & $\mathbf{3 0} \mathbf{~ m}$ & $\mathbf{4 0} \mathbf{~ m}$ & $\mathbf{5 0} \mathbf{~ m}$ & $\mathbf{6 0} \mathbf{~ m}$ & $\mathbf{7 0} \mathbf{~ m}$ \\
\hline \multirow{2}{*}{ OLSR } & $2.4 \mathrm{GHz}$ & $3.3 \%$ & $0 \%$ & $0 \%$ & $27 \%$ & $11 \%$ & $19 \%$ & $100 \%$ \\
& $5 \mathrm{GHz}$ & $6.6 \%$ & $30 \%$ & $44 \%$ & $6 \%$ & $20.4 \%$ & $100 \%$ & $100 \%$ \\
\hline \multirow{2}{*}{ BATMAN-ADV } & $2.4 \mathrm{GHz}$ & $0 \%$ & $0 \%$ & $13 \%$ & $22.1 \%$ & $44 \%$ & $73 \%$ & $27 \%$ \\
& $5 \mathrm{GHz}$ & $14 \%$ & $84 \%$ & $97 \%$ & $21.3 \%$ & $43 \%$ & $100 \%$ & $100 \%$ \\
\hline \multirow{2}{*}{ Babel } & $2.4 \mathrm{GHz}$ & $0 \%$ & $0 \%$ & $0 \%$ & $0 \%$ & $10 \%$ & $35 \%$ & $18 \%$ \\
& $5 \mathrm{GHz}$ & $8 \%$ & $36 \%$ & $45.9 \%$ & $15 \%$ & $29.7 \%$ & $100 \%$ & $100 \%$ \\
\hline
\end{tabular}

For the $2.4 \mathrm{GHz}$ band, as shown in the results, especially in Figures 3 and 4, the routing protocols present a different behavior. OLSR switches from direct communication to relay communication between the measurement points located at $40 \mathrm{~m}$ and $50 \mathrm{~m}$. However, both BATMAN-ADV and Babel switch between $60 \mathrm{~m}$ and $70 \mathrm{~m}$. This can be verified by the fact that there is a change of trend in the metrics studied at these two measurement points and the corresponding change in the routing table.

If we now focus on the $5 \mathrm{GHz}$ band, the trend change occurs between the measurement points located between 30 and $40 \mathrm{~m}$. Between these two points, communication switched from direct UAVs communication to relay mode. After this change in communication, the metrics improved, to rapidly decline again with distance. Additionally, for the $5 \mathrm{GHz}$ frequency band, the maximum distance at which we were able to establish communication 
between two nodes was $40 \mathrm{~m}$. This is again reflected above $40 \mathrm{~m}$, which is the distance at which the intermediate hop to the relay node existed. If the relay node had been located more than $40 \mathrm{~m}$ away, it would have been impossible to use it as an intermediate communication node in the $5 \mathrm{GHz}$ band.

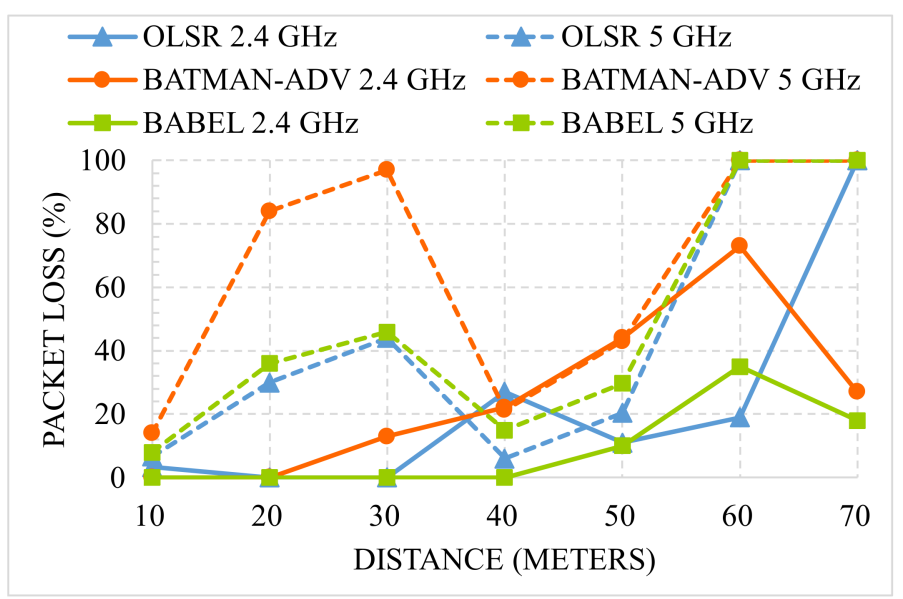

Figure 4. Average packet loss (\%) vs. distance (meters) for each protocol and frequency band.

We can conclude that Babel and OLSR obtained better results than BATMAN-ADV, given the results obtained. This may have been expected because BATMAN-ADV has a too-high routing update period that was originally not intended for FANETs. Finally, between Babel and OLSR, Babel offered the best overall performance, guaranteeing more stable results in both frequency bands.

\section{Conclusions}

The potential of FANETs can increase in the coming years with the advent of new communication technologies and standards such as 6G, the Internet of Things (IoT), and connected autonomous vehicles (CAVs). The benefits that FANETs can offer are immeasurable (coverage extension, application in emergency communications, search and rescue, agriculture, etc.). When deploying FANETs, it is essential to be able to find the path that a packet must follow to reach its destination. Due to the characteristic constant changes in the network topology of FANETs, the selection of the routing protocol is a crucial task for effective deployment and successful operation. After detailing the different routing protocols that have been proposed for FANETs, this paper performed a case study comparing the performance offered, in terms of throughput and packet loss, of three proactive routing protocols: OLSR, BATMAN-ADV, and Babel. The scenario studied could simulate a coverage extension scenario in emergencies, search and rescue, or remote surveillance. The results obtained showed that Babel achieved higher performance in the studied metrics, outperforming OLSR and BATMAN-ADV. Besides, it was shown that BATMAN-ADV performed significantly worse than OLSR and Babel due to its low frequency of routing-table updating. In particular, the sending period of messages in charge of finding alternative routes in BATMAN-ADV is $1 \mathrm{~s}$ (OGM interval). In FANETs, the network topology can vary a lot in $1 \mathrm{~s}$, hence discouraging its use for FANETs. As future work, we consider that an extension of the routing protocols to be evaluated would be a logical next step, employing a more significant number of UAVs with different characteristics and comparing experimental results and propagation models such as those presented in [77].

Author Contributions: Conceptualization, M.-D.C.; methodology, M.-D.C. and J.-C.S.-A.; software and tests measurements, A.G.-P., A.-M.M., and J.-C.S.-A.; formal analysis, A.-M.M. and M.-D.C.; writing, A.G.-P. and M.-D.C. All authors have read and agreed to the published version of the manuscript. 
Funding: This research was funded by the AEI/FEDER, UE project grant TEC2016-76465-C2-1-R (AIM), project SPID202000X116746SV0 (AriSe2: FINe), and 20740/FPI/18. Fundación Séneca. Región de Murcia (Spain).

Conflicts of Interest: The authors declare no conflict of interest. The funders had no role in the design of the study; in the collection, analyses, or interpretation of data; in the writing of the manuscript, or in the decision to publish the results.

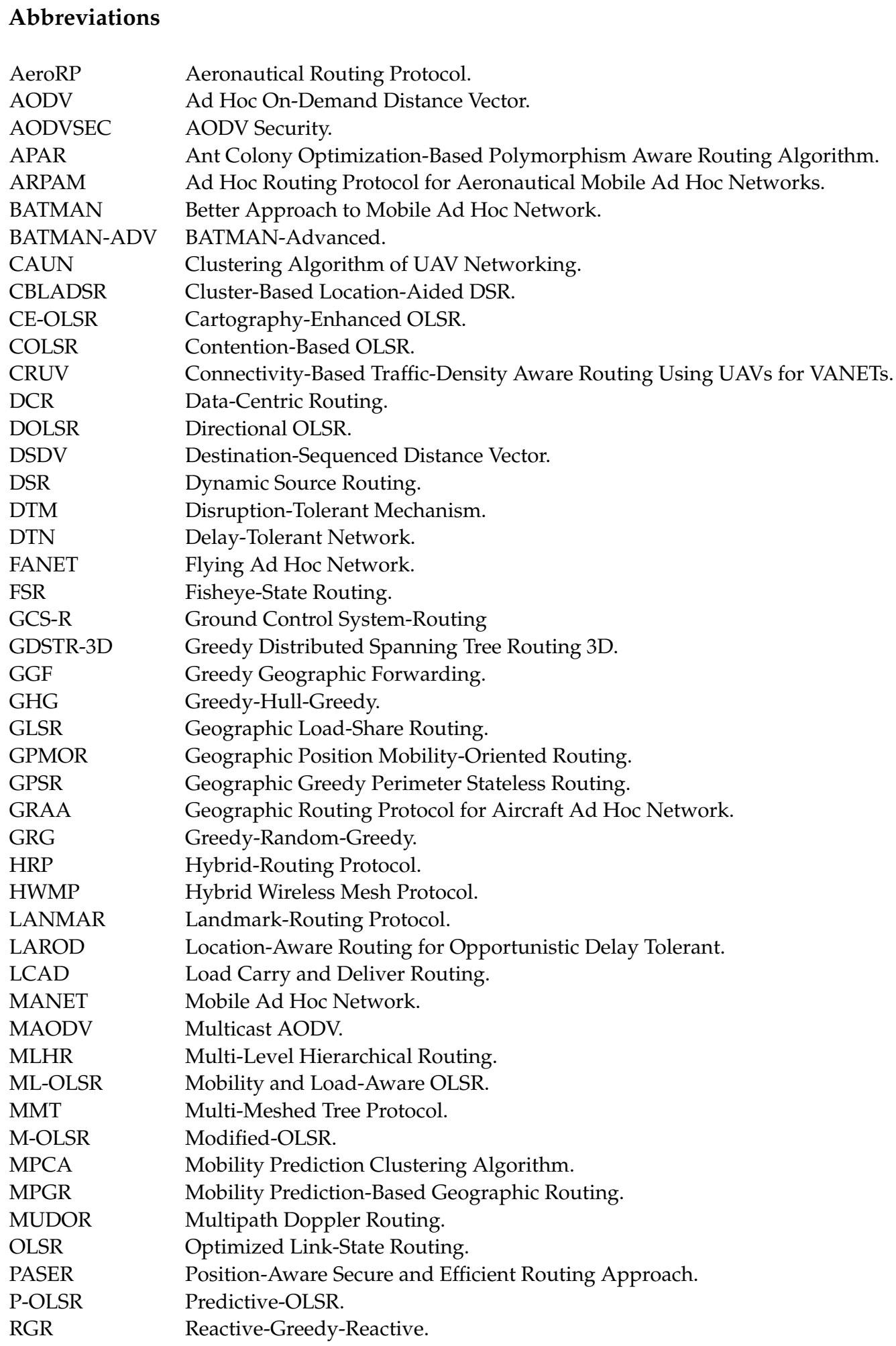




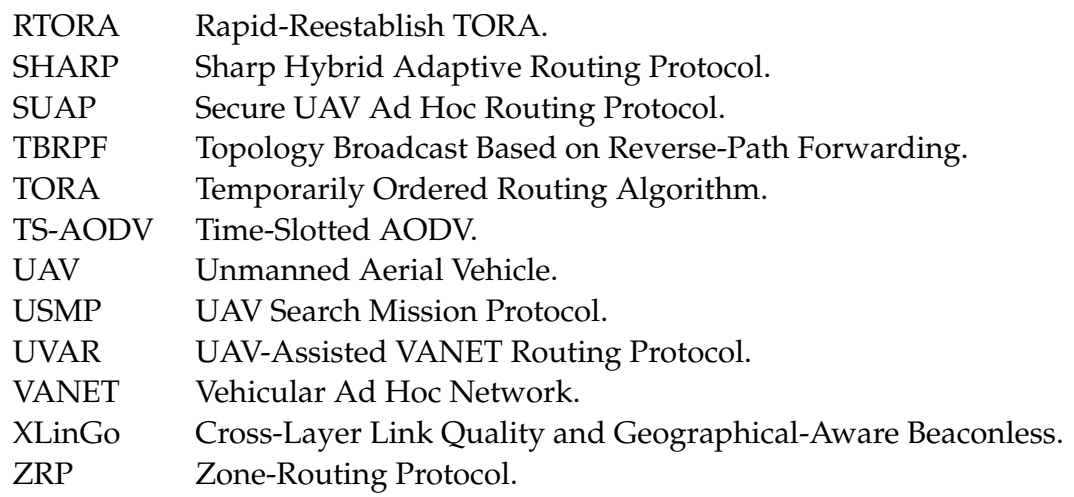

\section{References}

1. Guillen-Perez, A.; Cano, M.-D. Flying Ad Hoc Networks: A New Domain for Network Communications. Sensors 2018, 18 , 3571. [CrossRef] [PubMed]

2. Bekmezci, I.; Sahingoz, O.K.; Temel, Ş. Flying Ad-Hoc Networks (FANETs): A survey. Ad Hoc Netw. 2013, 11, 1254-1270. [CrossRef]

3. Oubbati, O.S.; Atiquzzaman, M.; Lorenz, P.; Tareque, H.; Hossain, S. Routing in Flying Ad Hoc Networks: Survey, Constraints, and Future Challenge Perspectives. IEEE Access 2019, 7, 81057-81105. [CrossRef]

4. Rosati, S.; Kruzelecki, K.; Heitz, G.; Floreano, D.; Rimoldi, B. Dynamic Routing for Flying Ad Hoc Networks. IEEE Trans. Veh. Technol. 2016, 65, 1690-1700. [CrossRef]

5. Rosati, S.; Kruzelecki, K.; Traynard, L.; Rimoldi, B. Speed-aware routing for UAV ad-hoc networks. In Proceedings of the 2013 IEEE Globecom Workshops (GC Wkshps), Atlanta, GA, USA, 9-13 December 2013; pp. 1367-1373.

6. Guillen-Perez, A.; Sanchez-Iborra, R.; Cano, M.-D.; Sanchez-Aarnoutse, J.C.; Garcia-Haro, J. WiFi networks on drones. In Proceedings of the 2016 ITU Kaleidoscope: ICTs for a Sustainable World (ITU WT), Bangkok, Thailand, 14-16 November 2016; pp. 1-8.

7. Lee, J.; Kim, K.; Yoo, S.; Chung, A.Y.; Lee, J.Y.; Park, S.J.; Kim, H. Constructing a reliable and fast recoverable network for drones. In Proceedings of the 2016 IEEE International Conference on Communications (ICC), Kuala Lumpur, Malaysia, 22-27 May 2016.

8. Kaysina, I.A.; Vasiliev, D.S.; Abilov, A.; Meitis, D.S.; Kaysin, A.E. Performance evaluation testbed for emerging relaying and coding algorithms in Flying Ad Hoc Networks. In Proceedings of the 2018 Moscow Workshop on Electronic and Networking Technologies (MWENT), Moscow, Russia, 14-16 March 2018.

9. Maxa, J.-A.; Ben Mahmoud, M.S.; Larrieu, N. Joint Model-Driven design and real experiment-based validation for a secure UAV Ad hoc Network routing protocol. In Proceedings of the 2016 Integrated Communications Navigation and Surveillance (ICNS), Herndon, VA, USA, 19-21 April 2016; pp. 1-16.

10. Maxa, J.A.; Mahmoud, M.S.B.; Larrieu, N. Survey on UAANET routing protocols and network security challenges. Ad-Hoc Sens. Wirel. Netw. 2017, 37, 231-320.

11. Cheng, C.-M.; Hsiao, P.-H.; Kung, H.T.; Vlah, D. Maximizing throughput of UAV-relaying networks with the load-carry-anddeliver paradigm. In Proceedings of the 2007 IEEE Wireless Communications and Networking Conference, Hong Kong, China, 11-15 March 2007; pp. 4417-4424. [CrossRef]

12. Sahingoz, O.K. Networking Models in Flying Ad-Hoc Networks (FANETs): Concepts and Challenges. J. Intell. Robot. Syst. 2014, 74, 513-527. [CrossRef]

13. Ko, J.; Mahajan, A.; Sengupta, R. A network-centric UAV organization for search and pursuit operations. In Proceedings of the IEEE Aerospace Conference, Big Sky, MT, USA, 9-16 March 2002; Volume 6, pp. 2697-2713.

14. Kolios, P.; Friderikos, V.; Papadaki, K. Store carry and forward relay aided cellular networks. In Proceedings of the Seventh International Workshop on Vehicular Ad Hoc Networks, VANET 2010, Chicago, IL, USA, 24 September 2010; pp. 71-72.

15. Abolhasan, M.; Wysocki, T.; Dutkiewicz, E. A review of routing protocols for mobile ad hoc networks. Ad Hoc Netw. 2004, 2, 1-22. [CrossRef]

16. Jacquet, P.; Muhlethaler, P.; Clausen, T.; Laouiti, A.; Qayyum, A.; Viennot, L. Optimized link state routing protocol for ad hoc networks. In Proceedings of the IEEE International Multi Topic Conference, IEEE INMIC 2001, Technology for the 21st Century, Lahore, Pakistan, 30-30 December 2001; pp. 62-68.

17. Perkins, C.E.; Bhagwat, P. Highly dynamic Destination-Sequenced Distance-Vector routing (DSDV) for mobile computers. ACM SIGCOMM Comput. Commun. Rev. 1994, 24, 234-244. [CrossRef]

18. Johnson, D.L.; Ntlatlapa, N.; Aichele, C. Simple pragmatic approach to mesh routing using BATMAN. In Proceedings of the 2nd IFIP International Symposium on Wireless Communications and Information Technology in Developing Countries, CSIR, Pretoria, South Africa, 6-7 October 2008; pp. 10-20.

19. Alshbatat, A.I.; Dong, L. Cross layer design for mobile Ad-Hoc Unmanned Aerial Vehicle communication networks. In Proceedings of the 2010 International Conference on Networking, Sensing and Control (ICNSC), Chicago, IL, USA, 10-12 April 2010; pp. 331-336. [CrossRef] 
20. Singh, K.; Verma, A.K. Experimental analysis of AODV, DSDV and OLSR routing protocol for flying adhoc networks (FANETs). In Proceedings of the 2015 IEEE International Conference on Electrical, Computer and Communication Technologies (ICECCT), Coimbatore, India, 5-7 March 2015; pp. 1-4.

21. Yadav, M.; Gupta, S.K.; Saket, R.K. Multi-hop wireless ad-hoc network routing protocols- a comparative study of DSDV, TORA, DSR and AODV. In Proceedings of the 2015 International Conference on Electrical, Electronics, Signals, Communication and Optimization (EESCO), Visakhapatnam, India, 24-25 January 2015; pp. 1-5. [CrossRef]

22. Broch, J.; Maltz, D.A.; Johnson, D.B.; Hu, Y.-C.; Jetcheva, J. A performance comparison of multi-hop wireless ad hoc network routing protocols. In Proceedings of the Fourth Annual ACM/IEEE International Conference on Mobile Computing and Networking (MobiCom'98), Dallas, TX, USA, 25-30 October 1998; pp. 85-97.

23. Pojda, J.; Wolff, A.; Sbeiti, M.; Wietfeld, C. Performance analysis of mesh routing protocols for UAV swarming applications. In Proceedings of the 2011 8th International Symposium on Wireless Communication Systems, Aachen, Germany, 6-9 November 2011; pp. 317-321.

24. Sanchez-Iborra, R.; Cano, M.-D.; Garcia-Haro, J. Performance Evaluation of BATMAN Routing Protocol for VoIP Services: A QoE Perspective. IEEE Trans. Wirel. Commun. 2014, 13, 4947-4958. [CrossRef]

25. Zheng, Y.; Jiang, Y.; Dong, L.; Wang, Y.; Li, Z.; Zhang, H. A mobility and load aware OLSR routing protocol for UAV mobile ad-hoc networks. In Proceedings of the 2014 International Conference on Information and Communications Technologies (ICT 2014), Nanjing, China, 15-17 May 2014; pp. 1-7.

26. Li, Y.; Luo, X. Cross layer optimization for cooperative mobile ad-hoc UAV network. Int. J. Digit. Content Technol. Appl. 2012, 6, 367-375.

27. Paul, A.B.; Nandi, S. Modified Optimized Link State Routing (M-OLSR) for Wireless Mesh Networks. In Proceedings of the 2008 International Conference on Information Technology, Bhubaneswar, India, 17-20 December 2008; pp. 147-152.

28. Belhassen, M.; Belghith, A.; Abid, M.A. Performance evaluation of a cartography enhanced OLSR for mobile multi-hop ad hoc networks. In Proceedings of the 2011 Wireless Advanced, London, UK, 20-22 June 2011; pp. 149-155. [CrossRef]

29. Bellur, B.; Ogier, R.G.; Templin, F.L. Topology broadcast based on reverse-path forwarding routing protocol (tbrpf). In ETF Internet Draft; RFC: Fremont, CA, USA, 2003.

30. Pei, G.; Gerla, M.; Chen, T.-W. Fisheye state routing: A routing scheme for ad hoc wireless networks. In Proceedings of the 2000 IEEE International Conference on Communications, ICC 2000, Global Convergence through Communications, Conference Record, New Orleans, LA, USA, 18-22 June 2000; pp. 70-74. [CrossRef]

31. Chroboczek, J. The Babel Routing Protocol. 2011. Available online: https://www.hjp.at/(en)/doc/rfc/rfc6126.html (accessed on 11 May 2021).

32. Johnson, D.B.; Maltz, D.A. Dynamic source routing in ad hoc wireless networks. In Mobile Computing; Springer: Boston, MA, USA, 2007; pp. 153-181.

33. Perkins, C.E.; Royer, E.M. Ad-hoc on-demand distance vector routing. In Proceedings of the 2nd IEEE Workshop on Mobile Computing Systems and Applications (WMCSA 1999), New Orleans, LA, USA, 25-26 February 1999; pp. 90-100.

34. Forsmann, J.H.; Hiromoto, R.E.; Svoboda, J. A time-slotted on-demand routing protocol for mobile ad hoc unmanned vehicle systems. In Proceedings of the SPIE 6561, Unmanned Systems Technology IX, Orlando, FL, USA, 2 May 2007; Volume 6561, p. 65611P. [CrossRef]

35. Royer, E. Multicast ad hoc on-demand distance vector (MAODV) routing. In IETF Internet Draft; RFC: Fremont, CA, USA, 2000.

36. Aggarwal, A. AODVSEC: A Novel Approach to Secure Ad Hoc On-Demand Distance Vector (AODV) Routing Protocol from Insider Attacks in MANETs. Int. J. Comput. Netw. Commun. 2012, 4, 191-210. [CrossRef]

37. Haas, P.; Pearlman, Z.J.; Samar, M.R. The Zone Routing Protocol (ZRP) for Ad Hoc Networks. In IETF Draft; RFC: Fremont, CA, USA, 2002; p. 11.

38. Park, V.; Corson, S. Temporally-Ordered Routing Algorithm (TORA) Version 1 Functional Specification. In IETF MANET Work. Gr. INTERNET-DRAFT; RFC: Fremont, CA, USA, 2002; pp. 1-23.

39. Zhai, Z.; Du, J.; Ren, Y. The Application and Improvement of Temporally Ordered Routing Algorithm in Swarm Network with Unmanned Aerial Vehicle Nodes. In Proceedings of the ICWMC 2013: The Ninth International Conference on Wireless and Mobile Communications, Nice, France, 21-26 July 2013; pp. 7-12.

40. Wei, Y.; Blake, M.B.; Madey, G.R. An Operation-Time Simulation Framework for UAV Swarm Configuration and Mission Planning. Procedia Comput. Sci. 2013, 18, 1949-1958. [CrossRef]

41. Ramasubramanian, V.; Haas, Z.J.; Sirer, E.G. SHARP: A Hybrid Adaptive Routing Protocol for Mobile Ad Hoc Networks. In Proceedings of the 4th ACM International Symposium Mobile ad hoc Network Computer-MobiHoc '03, Annapolis, MD, USA, 1-3 June 2013; p. 303.

42. Pei, G.; Gerla, M.; Hong, X.; Chiang, C.-C. A wireless hierarchical routing protocol with group mobility. In Proceedings of the 1999 IEEE Wireless Communications and Networking Conference (Cat. No.99TH8466), New Orleans, LA, USA, 21-24 September 1999; Volume 3, pp. 1538-1542. [CrossRef]

43. Shirani, R. Reactive-Greedy-Reactive in Unmanned Aeronautical Ad-Hoc Networks: A Combinational Routing Mechanism. Master's Thesis, Carleton University, Ottawa, ON, Canada, August 2011. 
44. Shirani, R.; St-Hilaire, M.; Kunz, T.; Zhou, Y.; Li, J.; Lamont, L. The Performance of Greedy Geographic Forwarding in Unmanned Aeronautical Ad-Hoc Networks. In Proceedings of the 2011 Ninth Annual Communication Networks and Services Research Conference, Ottawa, ON, Canada, 2-5 May 2011; pp. 161-166.

45. Iordanakis, M.; Yannis, D.; Karras, K.; Bogdos, G.; Dilintas, G.; Amirfeiz, M.; Colangelo, G.; Baiotti, S. Ad-hoc routing protocol for aeronautical mobile ad-hoc networks. In Proceedings of the Fifth International Symposium on Communication Systems, Networks and Digital Signal Processing (CSNDSP), Achaia, Greece, 19-21 July 2006; pp. 1-5.

46. Ni, M.; Zhong, Z.; Wu, H.; Zhao, D. A New Stable Clustering Scheme for Highly Mobile Ad Hoc Networks. In Proceedings of the 2010 IEEE Wireless Communication and Networking Conference, Sydney, NSW, Australia, 18-21 April 2010; pp. 1-6. [CrossRef]

47. Dora, D.P.; Kumar, S.; Kaiwartya, O. Efficient dynamic caching for geocast routing in VANETs. In Proceedings of the 2015 2nd International Conference on Signal Processing and Integrated Networks (SPIN), Noida, India, 19-20 February 2015; pp. 979-983.

48. Lin, L.; Sun, Q.; Li, J.; Yang, F. A novel geographic position mobility oriented routing strategy for UAVs. J. Comput. Inf. Syst. 2012, 8,709-716.

49. Lin, L.; Sun, Q.; Wang, S.; Yang, F. A geographic mobility prediction routing protocol for Ad Hoc UAV Network. In Proceedings of the 2012 IEEE Globecom Workshops, Anaheim, CA, USA, 3-7 December 2012; pp. 1597-1602. [CrossRef]

50. Medina, D.; Hoffmann, F.; Rossetto, F.; Rokitansky, C.-H. A Geographic Routing Strategy for North Atlantic In-Flight Internet Access Via Airborne Mesh Networking. IEEE/ACM Trans. Netw. 2011, 20, 1231-1244. [CrossRef]

51. Lidowski, R.L.; Mullins, B.E.; Baldwin, R.O. A novel communications protocol using geographic routing for swarming UAVs performing a Search Mission. In Proceedings of the 2009 IEEE International Conference on Pervasive Computing and Communications, Galveston, TX, USA, 9-13 March 2009; pp. 1-7.

52. Liu, C.; Wu, J. Efficient Geometric Routing in Three Dimensional Ad Hoc Networks. In Proceedings of the IEEE INFOCOM 2009-The 28th Conference on Computer Communications, Rio de Janeiro, Brazil, 19-25 April 2009; pp. $2751-2755$.

53. Flury, R.; Wattenhofer, R. Randomized 3D geographic routing. In Proceedings of the IEEE INFOCOM 2008-The 27th Conference on Computer Communications, Phoenix, AZ, USA, 13-18 April 2008; pp. 1508-1516.

54. Zhou, J.; Chen, Y.; Leong, B.; Sundaramoorthy, P.S. Practical 3D geographic routing for wireless sensor networks. In Proceedings of the 8th ACM Conference on Web Science, Zurich, Switzerland, 3-5 November 2010; pp. 337-350.

55. Oubbati, O.S.; Lakas, A.; Lagraa, N.; Yagoubi, M.B. CRUV: Connectivity-based traffic density aware routing using UAVs for VANets. In Proceedings of the 2015 International Conference on Connected Vehicles and Expo (ICCVE), Shenzhen, China, 19-23 October 2015; pp. 68-73. [CrossRef]

56. Oubbati, O.S.; Lakas, A.; Lagraa, N.; Yagoubi, M.B. UVAR: An intersection UAV-assisted VANET routing protocol. In Proceedings of the 2016 IEEE Wireless Communications and Networking Conference, Doha, Qatar, 3-6 April 2016; pp. 1-6. [CrossRef]

57. Sbeiti, M.; Goddemeier, N.; Behnke, D.; Wietfeld, C. PASER: Secure and Efficient Routing Approach for Airborne Mesh Networks. IEEE Trans. Wirel. Commun. 2016, 15, 1950-1964. [CrossRef]

58. Rosário, D.; Zhao, Z.; Braun, T.; Cerqueira, E.; Santos, A.; Alyafawi, I. Opportunistic routing for multi-flow video dissemination over Flying Ad-Hoc Networks. In Proceedings of the IEEE International Symposium on a World of Wireless, Mobile and Multimedia Networks 2014, Sydney, NSW, Australia, 19 June 2014; pp. 1-6. [CrossRef]

59. Liu, K.; Zhang, J.; Zhang, T. The clustering algorithm of UAV Networking in Near-space. In Proceedings of the 2008 8th International Symposium on Antennas, Propagation and EM Theory, Kunming, China, 2-5 November 2008; pp. 1550-1553.

60. Zang, C.; Zang, S. Mobility prediction clustering algorithm for UAV networking. In Proceedings of the 2011 IEEE GLOBECOM Workshops (GC Wkshps), Houston, TX, USA, 5-9 December 2011; pp. 1158-1161. [CrossRef]

61. Pei, G.; Gerla, M.; Hong, X. LANMAR: Landmark routing for large scale wireless Ad Hoc Networks with group mobility. In Proceedings of the 2000 First Annual Workshop on Mobile and Ad Hoc Networking and Computing, MobiHOC (Cat. No.00EX444), Boston, MA, USA, 11 August 2000; pp. 11-18.

62. Martin, N.; Al-Mousa, Y.; Shenoy, N. An Integrated Routing and Medium Access Control Framework for Surveillance Networks of Mobile Devices. Comput. Vis. 2011, 6522, 315-327. [CrossRef]

63. Shi, N.; Luo, X. A Novel Cluster-Based Location-Aided Routing Protocol for UAV Fleet Networks. Int. J. Digit. Content Technol. Appl. 2012, 6, 376-383. [CrossRef]

64. Fu, B.; Dasilva, L.A. A mesh in the sky: A routing protocols for airbone networks. In Proceedings of the MILCOM 2007-IEEE Military Communications Conference, Orlando, FL, USA, 29-31 October 2007; pp. 1-7.

65. Leonov, A.V. Application of bee colony algorithm for FANET routing. In Proceedings of the 2016 17th International Conference of Young Specialists on Micro/Nanotechnologies and Electron Devices (EDM), Erlagol, Russia, 30 June-4 July 2016 ; pp. 124-132. [CrossRef]

66. Leonov, A.V. Modeling of bio-inspired algorithms AntHocNet and BeeAdHoc for Flying Ad Hoc Networks (FANETs). In Proceedings of the 2016 13th International Scientific-Technical Conference on Actual Problems of Electronics Instrument Engineering (APEIE), Novosibirsk, Russia, 3-6 October 2016; Volume 2, pp. 90-99. [CrossRef]

67. Yu, Y.; Ru, L.; Chi, W.; Liu, Y.; Yu, Q.; Fang, K. Ant colony optimization based polymorphism-aware routing algorithm for ad hoc UAV network. Multimedia Tools Appl. 2016, 75, 14451-14476. [CrossRef]

68. Kuiper, E.; Nadjm-Tehrani, S. Geographical Routing with Location Service in Intermittently Connected MANETs. IEEE Trans. Veh Technol. 2010, 60, 592-604. [CrossRef] 
69. Jabbar, A.; Sterbenz, J.P.G. AeroRP: A Geolocation Assisted Aeronautical Routing Protocol for Highly Dynamic Telemetry Environments. In Proceedings of the International Telemetering Conference, Las Vegas, NV, USA, 26-29 October 2009; pp. 1-10.

70. Hyeon, S.; Kim, K.-I. A new geographic routing protocol for aircraft ad hoc networks. In Proceedings of the 29th Digital Avionics Systems Conference, Salt Lake City, UT, USA, 3-7 October 2010; pp. 1-8. [CrossRef]

71. Whitbeck, J.; Conan, V. HYMAD: Hybrid DTN-MANET routing for dense and highly dynamic wireless networks. Comput. Commun. 2010, 33, 1483-1492. [CrossRef]

72. Burgess, J.; Gallagher, B.; Jensen, D.; Levine, B.N. MaxProp: Routing for Vehicle-Based Disruption-Tolerant Networks. In Proceedings of the IEEE INFOCOM 2006, 25th IEEE International Conference on Computer Communications, Barcelona, Spain, 23-29 April 2006; Volume 6, pp. 1-11. [CrossRef]

73. Spyropoulos, T.; Psounis, K.; Raghavendra, C.S. Spray and wait: An efficient routing scheme for intermittently connected mobile networks. In Proceedings of the ACM SIGCOMM 2005 Work, Delay-Tolerant Networking, WDTN 2005, Philadelphia, PA, USA, 22-26 August 2005; pp. 252-259.

74. Lindgren, A.; Doria, A.; Schelén, O. Probabilistic routing in intermittently connected networks. ACM SIGMOBILE Mob. Comput. Commun. Rev. 2003, 7, 19-20. [CrossRef]

75. mqmaker. WiTi Board. Available online: https://goo.gl/bfSvM8 (accessed on 4 December 2017).

76. Iperf. Available online: https:/ /iperf.fr/ (accessed on 20 May 2016).

77. Khawaja, W.; Guvenc, I.; Matolak, D.W.; Fiebig, U.-C.; Schneckenburger, N. A Survey of Air-to-Ground Propagation Channel Modeling for Unmanned Aerial Vehicles. IEEE Commun. Surv. Tutor. 2019, 21, 2361-2391. [CrossRef] 